\title{
Arc characteristics of GTAW under high pressure
}

\author{
SHAOJIE WU, SHAN GONG and HONGMING GAO*
}

State Key Laboratory of Advanced Welding and Joining, Harbin Institute of Technology, West Straight Sreet 92, Harbin 150001, People's Republic of China

e-mail: gaohm@hit.edu.cn

MS received 4 June 2018; revised 4 December 2018; accepted 10 December 2018; published online 26 February 2019

\begin{abstract}
The characteristics of GTA (gas tungsten arc) under high pressure has been studied in this paper to reveal the special arc phenomenon from the ambient pressure. A totally new hyperbaric GTAW experiment system has been built, including a hyperbaric environment simulator (0.1-3.5 MPa), an automatic GTAW machine with cooling, the moving equipment, a camera with filter and a central control unit. The arc morphology, the electric static characteristic, the arc voltage and arc length are studied with the increment of ambient pressure from 0.1 to $3.5 \mathrm{MPa}$, respectively. The relationship between the ambient pressure and the arc voltage is deduced according to the balance of heat-input and heat-output. The deduced function also verified the results from the welding experiment.
\end{abstract}

Keywords. High pressure; GTA; electrical characteristic; heat balance.

\section{Introduction}

$21^{\text {st }}$ century is called to be the century of the ocean. A lot of significant projects including pipe line for undersea oil transform, drilling platform, huge ocean ship and so on are conducted in/underneath the ocean even in thousands of meters [1, 2], which have already changed our daily life effectively. However, ocean also brings many problems such as the machinery should be well sealed and may need more maintenance because of the corrosivity. In general, the sealing of the machinery is designed well before putting it underwater. Hence how to maintain the machinery is the key to develop technology and use the ocean in the future. It is obvious that maintaining directly in/underneath the ocean is more efficient and economic [3-5]. Most machinery is built by metals, welding becomes the main method to repair the possible damaged parts.

However, it is impossible to send a skilled welder under the deep ocean as nobody could bare such a high-pressure. Fortunately, In the recent years, most company or government have already found a solution to solve this problem. In the first, a sealed cabin could be sent to the working position; and then drain the water out of the cabin such that a high-pressure fully-gassy space will be created; and then the mechanical arm could work instead of the skilled welder to repair the broken parts.

Although a high-pressure fully-gassy space is created, the welding process and its characters in the high-pressure condition may be totally different than in the normal

*For correspondence pressure environment, especially for the geometry of the arc and electrical characteristics which have considerable influence in determining the welding parameters, for example, arc length and current [6-9]. Researchers around the world have already done some experiments to study the welding process in high-pressure condition.

Allum et al in Cranfield University have studied the GTAW behavior of arc radiation, electric field intensity and density of current under the pressure of 1-42 bar (equal to $10 \mathrm{~m}-420 \mathrm{~m}$ depth). They find that in the same current and arc length, the arc voltage in high pressure is much higher than in the normal pressure, as well the density of current in the arc is more concentrated than in the normal pressure, especially in the center of the arc [10]. Allum et al believe that it is conducted by the arc shrink.

Hasui and Suga et al also studied the GTAW with shielding gas $\mathrm{Ar}$ and $\mathrm{He}$ in the range of 0.1-5 MPa. They find the same principle as Allum et al in addition to the gradient of current density decreased when the pressure in a high range as shown in figures 1 and 2 . The arc also attains high intensity and becomes brighter and unsteady in high pressure [11, 12]. With the increase of the pressure and current, the wastage of tungsten electrode becomes much quicker especially when the pressure is over $2.1 \mathrm{MPa}$, the wastage speed increased roughly. It is because the arc morphology shrinks in the high pressure such that the cathode spot is constrained in the top of electrode, the electrode burns harder by the increase of the arc-heat.

Nixon summarizes the formal experimental results and proposed an empirical equation in "Underwater repair technology" [13] as given below 


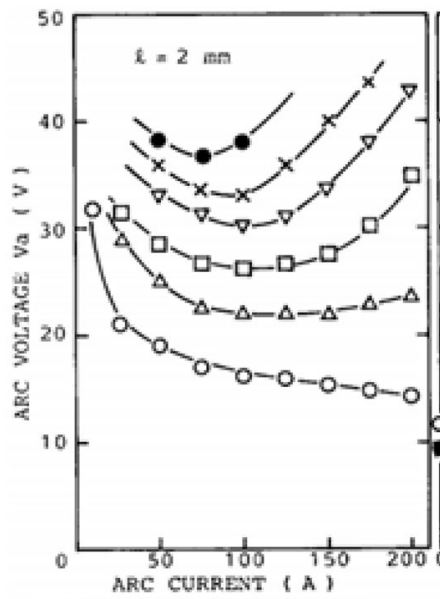

(a) I-Va characteristics

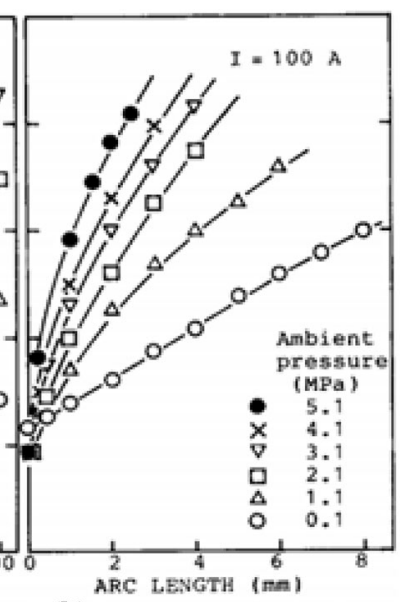

(b) \&-Va characteristies

Figure 1. The effect of arc electrical characteristics with the arc pressure [11].

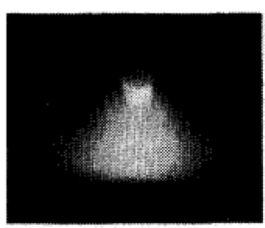

$0.1 \mathrm{MPa}$

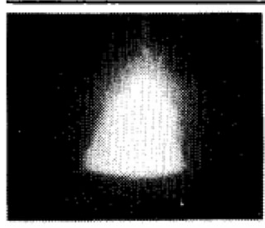

$3.1 \mathrm{MPa}$

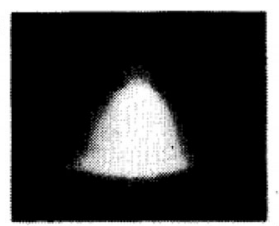

$1.1 \mathrm{MPa}$

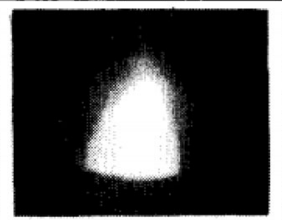

$4.1 \mathrm{MPa}$

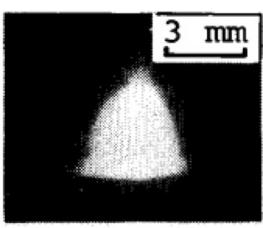

$2.1 \mathrm{MPa}$

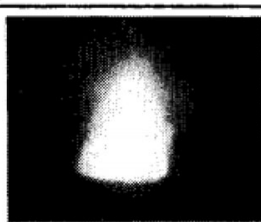

$5.1 \mathrm{MPa}$

Figure 2. The effect of the geometry of the arc with the arc pressure [11].

$$
U_{A B o}=U_{0}+E L \sqrt{10 P}
$$

Where $P$ is ordinary pressure, $U$ is voltage, $E$ is electric field intensity in ordinary pressure, $L$ is arc length.

Jiang $\mathrm{L}$ and Jiao $\mathrm{X}$ et al and ChunjianWang in Beijing Institute of Petrochemical Technology find the electrical characteristics showing raising characteristic over $50 \mathrm{~A}$, and even more higher with the increase of pressure, the intensity of electric field in arc column and the cathode and anode electric pressure increase $[14,15]$.

To have a comprehensive and accurate knowledge about the arc behavior in the high-pressure condition, GTAW process is studied in this project. A totally new hyperbaric GTAW welding experiment system is built to achieve the requirements, the system includes of hyperbaric environment simulator, automatic welding equipment, assistive equipment and central control unit. This system could finish the research experiments under 0.1-3.5 MPa. The current and voltage are recorded during experiments, a CCD

camera will take photos of the geometry of the arc in realtime. This paper also deduces the relationship between the environment pressure and arc voltage based on the heat balance. The deduced equation also explains the experimental results.

This paper is organized as follows. Section 2 describes the experimental system, measurement system and signal collecting system. The effect of high-pressure in arc morphology and electric characteristics are shown in section 3. The analytic equation is deduced in "Theoretical Analysis" of section 4 . The conclusions are provided in section 5 .

\section{Experimental procedure}

A totally new hyperbaric GTAW welding experiment system is built for this project, the sketch of this system is shown in figure 3(a), the actual photo is shown in figure 3(b). This system contains hyperbaric environment simulator, automatic welding equipment, assistive equipment and central control unit. The volume of this simulator is $0.6 \mathrm{~m}^{3}$, maximum pressure is $5.0 \mathrm{MPa}$ (equal to $500 \mathrm{~m}$ depth under the water). In order to completely simulate the actual situation, before doing an experiment, the air will be drained out first until the pressure decreased to $0.03 \sim 0.05 \mathrm{MPa}$, then the argon (Ar) will be aerated into the simulator until reached the desired value. Although the simulator is already filled of inert air Ar, the shield air still applies during experiments to make sure the arc is steady, the rate of flow is $12 \mathrm{~L} / \mathrm{min}$.

The measurement system and signal collecting systems are also built to observe the arc morphology and acquire the electric static characteristics. The sketch of these systems is shown in figure 4 . The CCD camera is placed outside the simulator in front of a high-transparent glass, the photos will be taken 300 per second.

\section{Experiments and analysis}

\subsection{Arc morphology}

The arc morphology which is the most explicit phenomenon effected by the increase of environment pressure is taken by the CCD camera. The flow of shield gas and the arc length is constant as shown in table 1 . The brightness of arc is receded but not much to display an integrated arc morphology. The detail experiment parameters are shown in table 1. The photos of arc morphology in different pressure are shown in figure 5 .

From the photos, it is clear that the arc shrinks with the increase of the pressure. In the normal pressure as in figure 5(a), the arc looks like a bell; and then the pressure increases to $0.5 \mathrm{Mpa}$ as in figure $5(\mathrm{~b})$, there is no clear difference with figure 5(a). But when the pressure comes to $0.9 \mathrm{Mpa}$, the bottom of the arc shrinks that makes the arc 


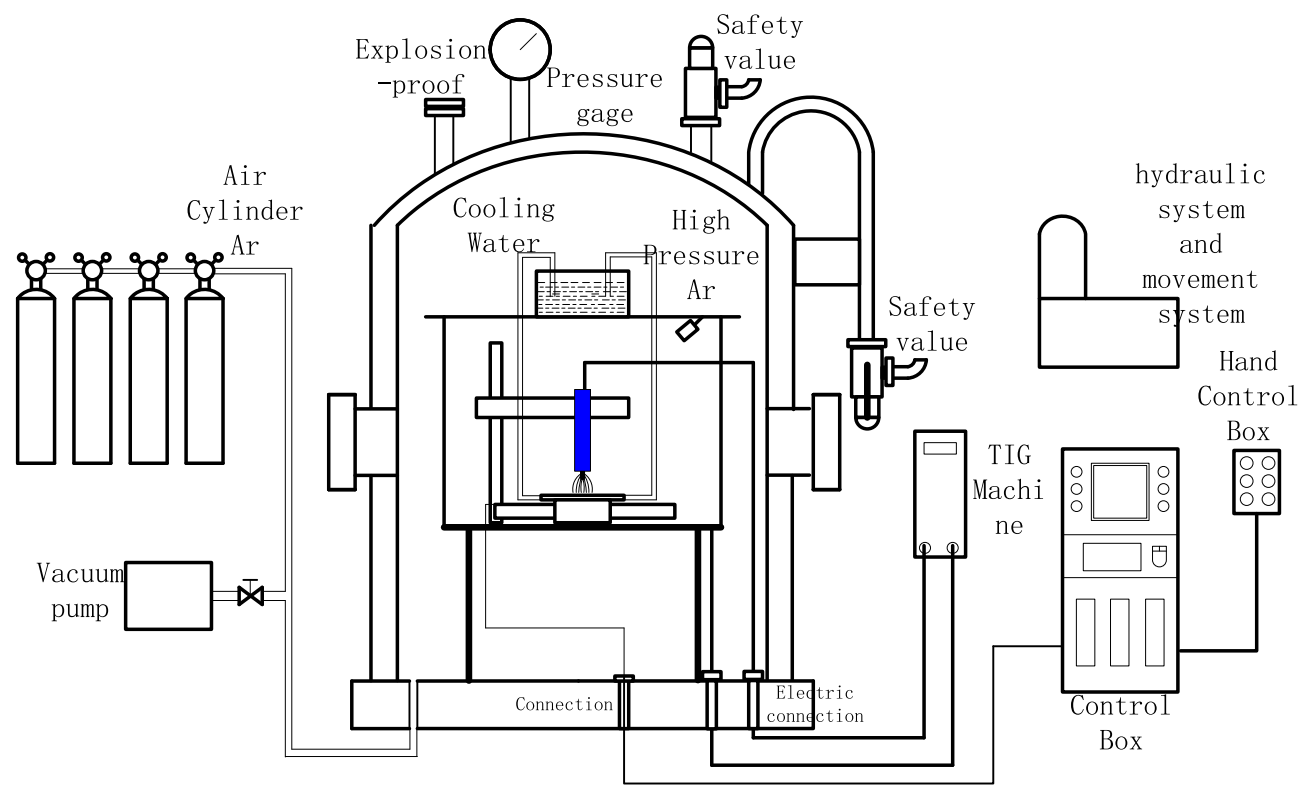

(a) The sketch of experimental system

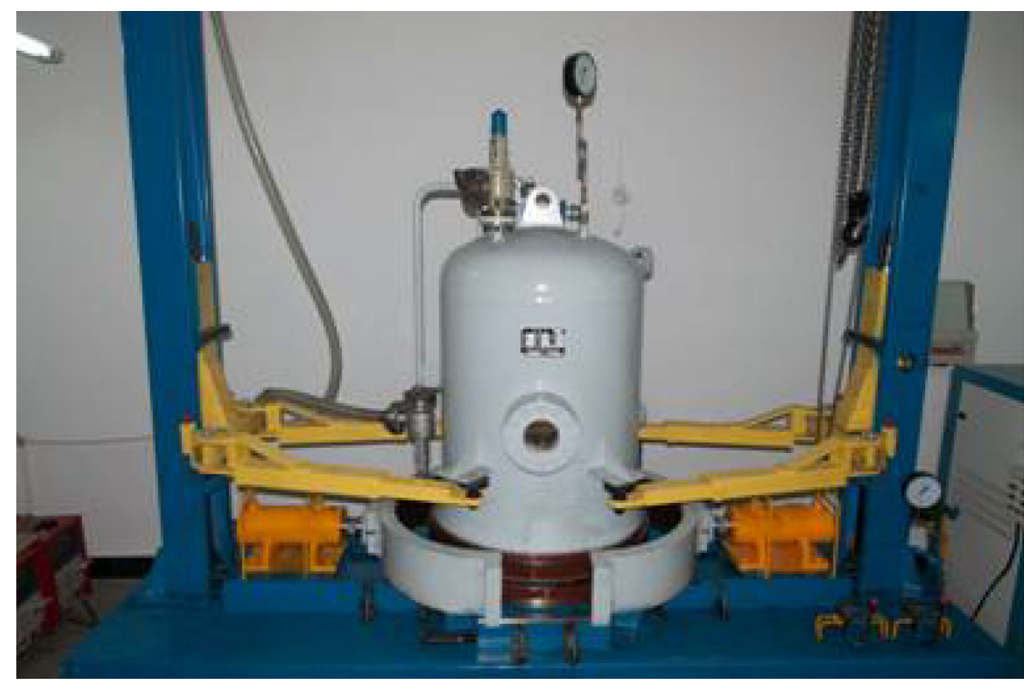

(b) The photo of the system

Figure 3. The hyperbaric GTAW welding experiment system.

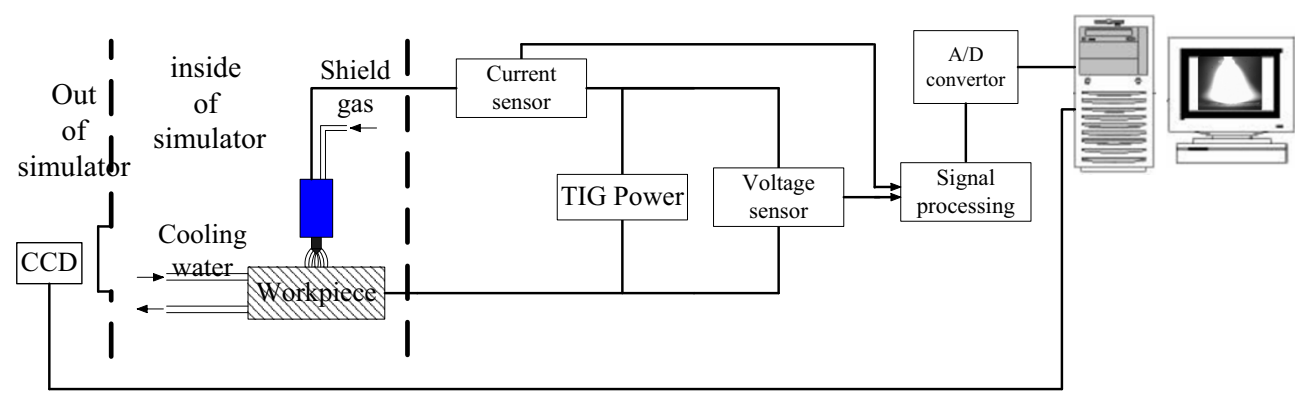

Figure 4. The sketch of the measurement system and signal collecting system. 
Table 1. Experimental parameters.

\begin{tabular}{lcccccc}
\hline Pressure/MPa & 0.1 & 0.5 & 0.9 & 1.5 & 1.9 & 2.3 \\
\hline Arc length/mm & 4 & 4 & 4 & 4 & 4 & 4 \\
Current/A & 150 & 150 & 150 & 150 & 150 & 150 \\
Voltage/V & 14.2 & 19.1 & 24.9 & 27.2 & 30.9 & 32.1 \\
\hline
\end{tabular}

looks like a cylinder, In the meanwhile, the top of the arc becomes a little expanded; When the pressure is up to 2.3 $\mathrm{MPa}$, it is already hard to distinguish the tungsten electrode from the photos, the top of the arc seems as wide as the bottom. It can be explained as the temperature of the arc is raised such that the tungsten top will tend to round rather than peaked, the conductive path from tungsten becomes wide and as a result, the top of arc looks like expanded.

\subsection{The electric static characteristic}

The electric static characteristics present the relationship between welding current and arc voltage which also reflects electric conductivity. As widely known, the larger the gradient of the curve is, the better the conductivity is. The curve also has reflected the steady ability of the arc and the balance of heat-input and output. The electric static characteristic in different pressure as 0.1-3.0 MPa are shown in figure 5. The current is changed from $50 \mathrm{~A}$ to $200 \mathrm{~A}$. The arc length is $4 \mathrm{~mm}$ in figure 5(a) and $6 \mathrm{~mm}$ in figure $5(\mathrm{~b}$ ).
As shown in figure 6, the curve displays as rising characteristics and the gradient of the curve increases little as the pressure increases. The gradient could also reflect the ionization ability and the power required, in this case, the ionization becomes hard when the pressure increases especially when the current is also increased.

\subsection{The arc voltage}

The relationship between environment pressure and arc voltage is shown in figure 7 . The current is constant in $150 \mathrm{~A}$ and $100 \mathrm{~A}$, the arc length is $4 \mathrm{~mm}$ in figure $7(\mathrm{a})$ and $6 \mathrm{~mm}$ in figure 7(b). The pressure is changed from $0.1 \mathrm{MPa}$ to $3.5 \mathrm{MPa}$.

From figures, it is obvious that the arc voltage is increased with the increase of pressure when the current is constant. For the pressure of $3.0 \mathrm{MPa}$ and arc length of $4 \mathrm{~mm}$, the arc voltage will be like $37 \mathrm{~V}$ at $150 \mathrm{~A}$ which is almost 3 times higher than at $0.1 \mathrm{MPa}$. As known before, the increase of the voltage means the more energy is needed to ionize the gas. In other words, more energy is needed when the environment pressure is increased. It is because the electric conductive path is decreased with the shrinking of the arc such that the electron should move faster to maintain the same arc current. Hence, the increased voltage which brings a higher electric field could accelerate the electron to the required speed. The higher pressure also stands for more particles in the working area, so that the conduction of the arc is also improved caused by the enhancement of the transition among the particles.

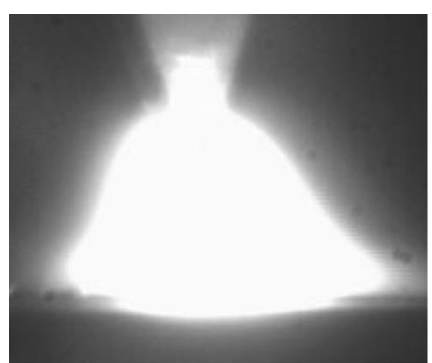

(a) $0.1 \mathrm{MPa}$

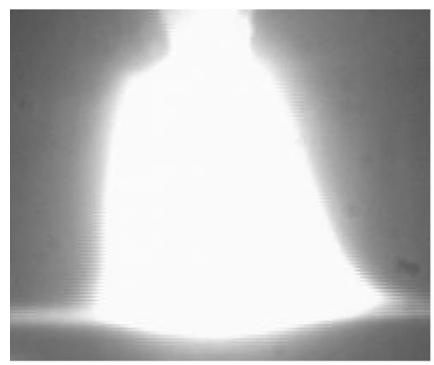

(d) $1.5 \mathrm{MPa}$

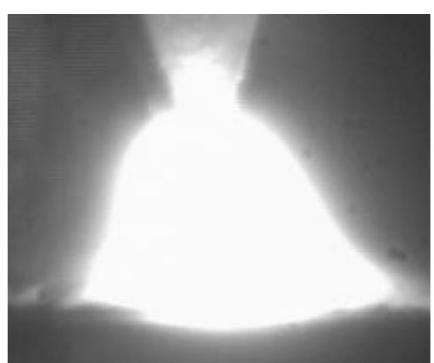

(b) $0.5 \mathrm{MPa}$

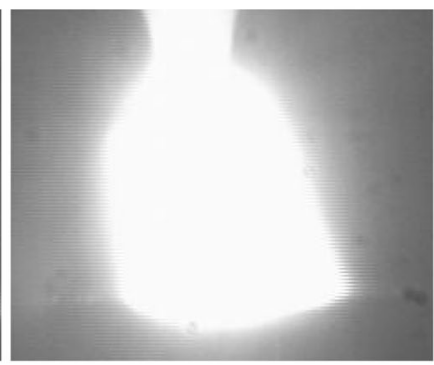

(e) $1.9 \mathrm{MPa}$

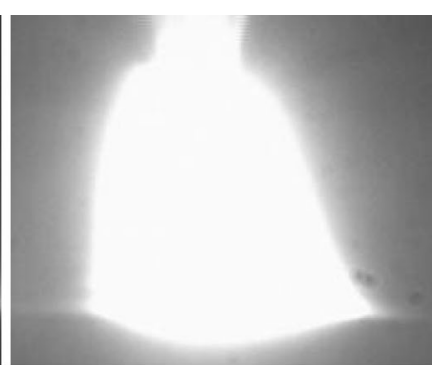

(c) $0.9 \mathrm{MPa}$

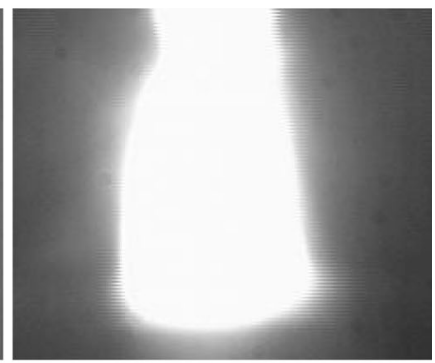

(f) $2.3 \mathrm{MPa}$

Figure 5. The arc morphology in different environment pressures. 


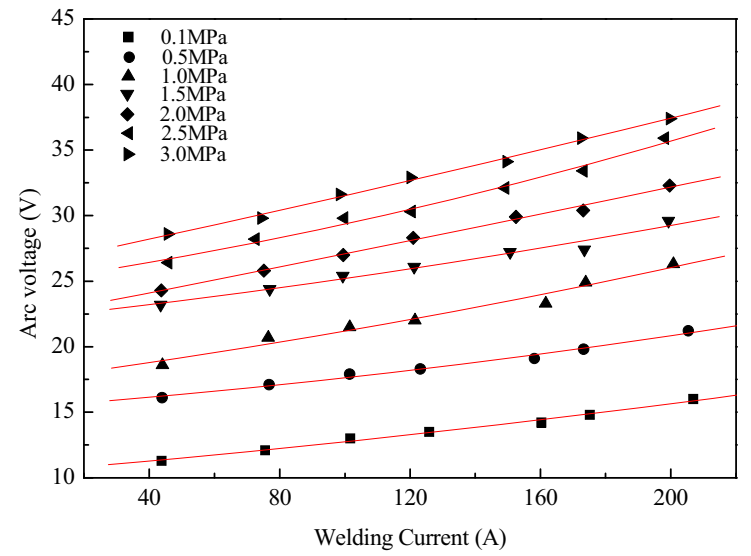

(a) Arc length: $4 \mathrm{~mm}$

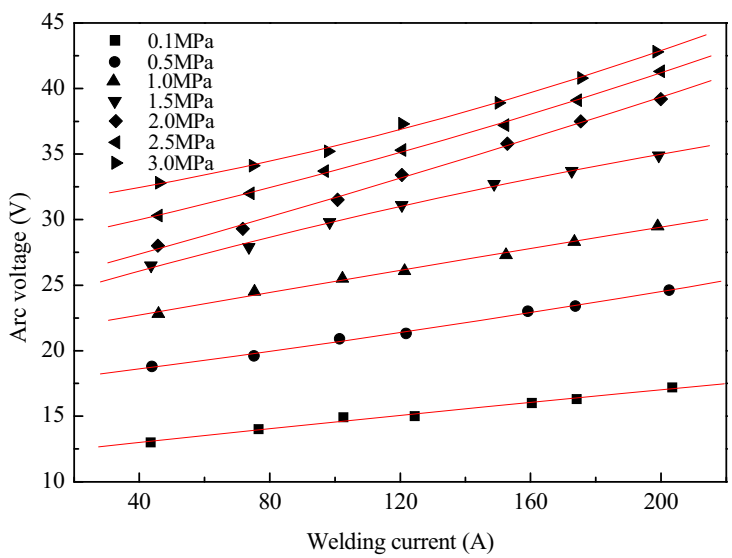

(b) Arc length: $6 \mathrm{~mm}$

Figure 6. The electric static characteristics in different pressure.

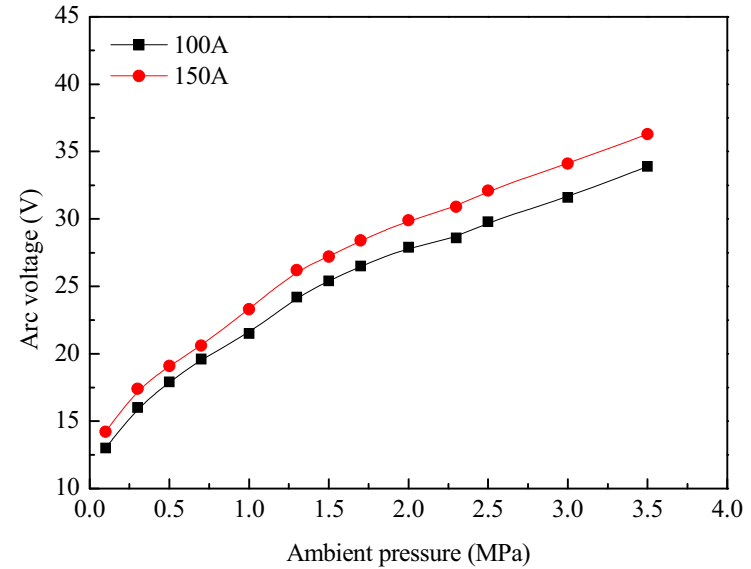

(a) Arc length: $4 \mathrm{~mm}$

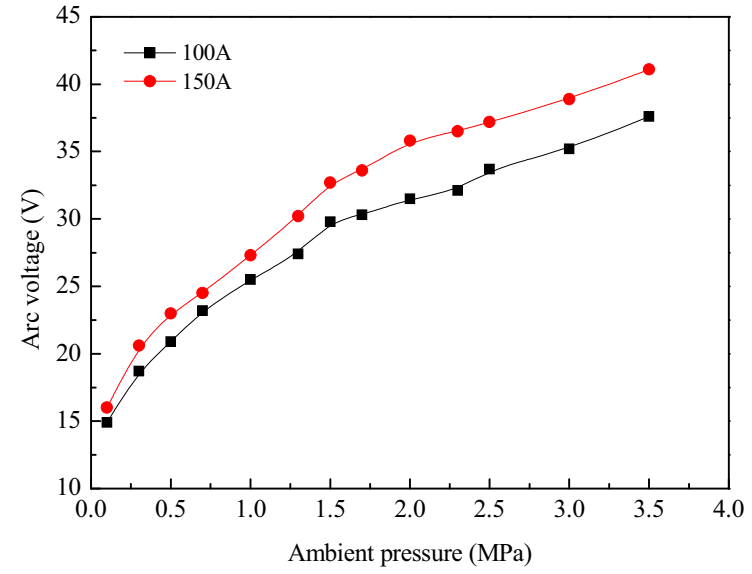

(b) Arc length: $6 \mathrm{~mm}$

Figure 7. The relationship between environment pressure and arc voltage.

\subsection{Arc length}

The arc voltage increases with the increase of arc length as linear in the normal pressure. For high-pressure, the relationship is shown in figure 8 .

From figures, it can be seen that the linearity between the arc length and arc voltage still maintains in the higher pressure and all the gradients are almost equaled. In general, the increase of the arc length may change the arc morphology from bell to cylinder shapes as well as the electric conductivity and temperature distribution. In this conduction, the electric conductivity does not change much.

However, the mathematical relationship between the arc voltage and the ambient pressure cannot be simply achieved from the experiments. It is reasonable to guess whether the relationship is affected by all the related inputs or can be deduced directly as a one-to-one correspondence.
In the next section, the authors will attempt to build the relationship based on the heat balance.

\section{Theoretical analysis and discussion}

Authors deduced the relationship between arc voltage and environment pressure based on the balance of heat-input and heat-output. During the TIG process, the heat-input and heat-output should be balanced such that the penetration depth could be kept constant. In general, the heat dissipates through conduction, convection and radiation, the sketch of the balance is shown in figure 9. It can also be shown as in the following equation.

$$
U I=Q_{C V}+Q_{C D}+Q_{R}
$$

The convection between the arc and the ambient air as axial and can be expressed as: 


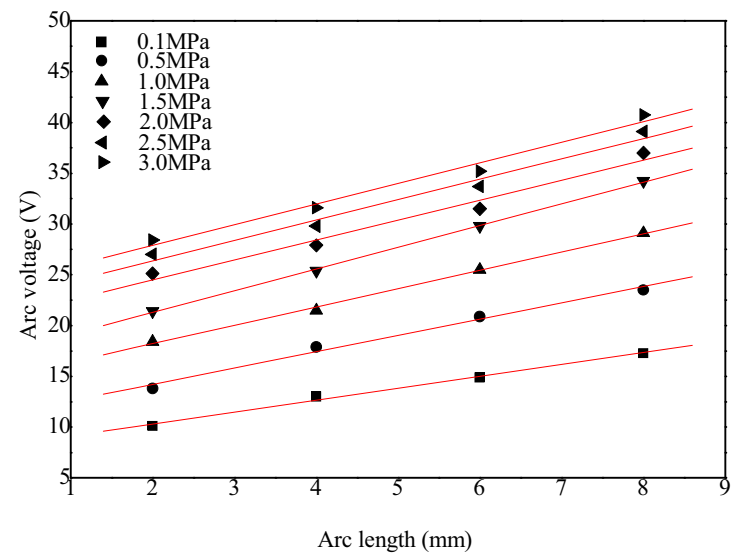

(a) Current: $100 \mathrm{~A}$

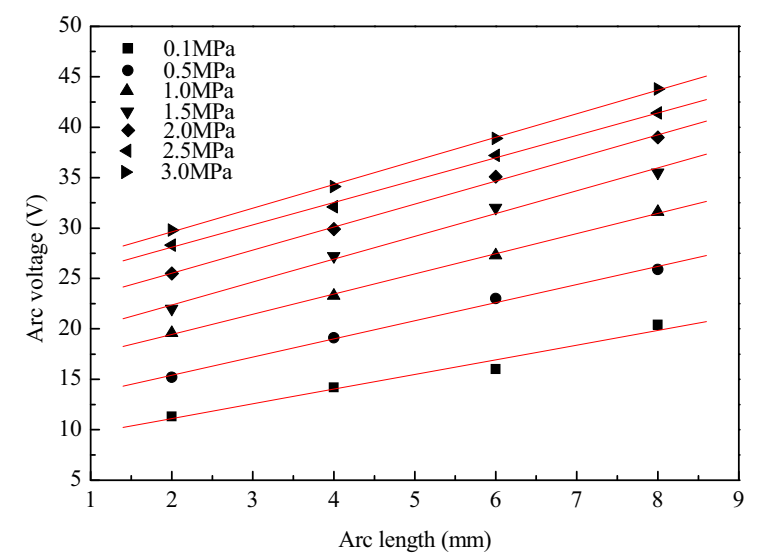

(b) Current: $150 \mathrm{~A}$

Figure 8. The arc voltage varied with the arc length.

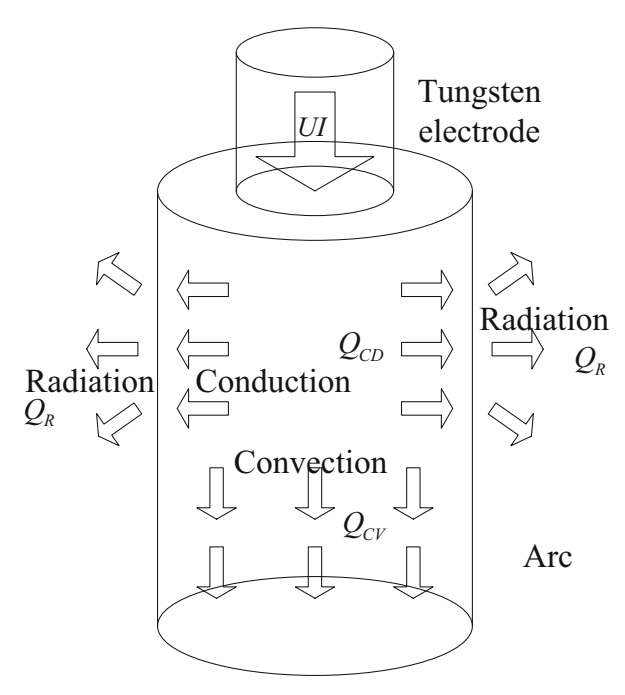

Figure 9. The sketch of the heat balance.

$$
Q_{C V}=n \times \bar{H}_{0}
$$

Where $n$ is the density of the particle crossed the arc-section per second; $\bar{H}_{0}$ is average heat transferred from the single particle to ambient air. The $n$ can also calculated by:

$$
n=N \bar{v} \times \pi R^{2}=\beta \pi P N_{0} \bar{v} R^{2} / P_{0}
$$

Where $\beta$ is the scale coefficient; $N_{0}$ is the density of the particle in normal state; $\bar{v}$ is the average speed of particle in arc; $P_{0}$ is the normal pressure. Hence the eq. (2) can be shown as:

$$
Q_{C V}=\beta \pi P N_{0} \bar{v} R^{2} \bar{H}_{0} / P_{0}
$$

Based on the Fourier conduction function, the heat transfer from arc plasma to external environment can be written as:

$$
Q_{C D}=\int_{S_{n}} \kappa \frac{\partial T}{\partial n} d S_{n}
$$

Where $\kappa$ is the coefficient of conduction.

In this case, we assume that the surface of arc is isothermal condition. Hence the conduction from arc surface to ambient air can be computed as the following function:

$$
Q_{C D}=\bar{\kappa} \times 2 \pi R l \times \Delta T
$$

Where $\bar{\kappa}$ is the average thermal conductivity; $2 \pi R l$ is the surface area of arc; $\Delta T$ is the difference of temperature between the center with the surface of arc.

The radiation is the most important method to dissipate heat. It can be calculated as follows:

$$
Q_{R}=\int_{V} q(T, P) d V
$$

Where $Q_{R}$ is the heat dissipated by radiation; $T$ is the temperature; $P$ is ambient pressure; $V$ is the volume.

Bauder et al find the density of the plasma is in direct proportion to the high pressure [16], as follows:

$$
q(T, P) \approx P q(T)
$$

Hence the eq.(6) could be written as:

$$
Q_{R}=\pi R^{2} l \times P \overline{q(T)}
$$

Where $\pi R^{2} l$ is the volume of plasma in arc, $\overline{q(T)}=$ $\frac{1}{V} \int_{V} q(T) d V$ is the average density.

The Eq. (1) can be expressed by Eq. (4), Eq. (6) and eq. (9) as:

$$
U I=\frac{\beta \pi P N_{0} \bar{v} R^{2} \bar{H}_{0}}{P_{0}}+\bar{\kappa} \times 2 \pi R l \times \Delta T+\pi R^{2} l \times P \overline{q(T)}
$$


According to Bauder [16], the radiation is the most important method to dissipate heat. However, the conduction and convection cannot be totally ignored, the balance function can be displayed as:

$$
U I \approx \pi R^{2} l \times P q(T)+Q_{0}
$$

Where $Q_{0}$ is the heat-output from both convection and conduction.

Allum et al proposed an experimental function between the TIG arc diameter with the ambient pressure according to experimental results as given below [10]:

$$
R=R_{0} \times P^{-n}(n>0)
$$

Hence, the relationship between arc voltage and ambient pressure can be expressed as:

$$
U=\frac{\pi R_{0}^{2} \bar{q}}{I} \times P^{1-2 n} \times l+\frac{Q_{0}}{I}
$$

From the eq. (13), the arc voltage $U$ is linear with both arc length and ambient pressure.

It is well known that the arc voltage is linear affected by the arc length in the normal condition from the experimental results and eq. (13), the linear relation is also conformed in high-pressure. However, the relationship between arc voltage and ambient pressure is more similar to root function from figure 7 . The assumption can be proved, and the approximate equation is deduced as in eq. (13). By using this function, the arc voltage will be easily predicted when the arc length and ambient pressure is determined especially in the high-pressure.

\section{Conclusions}

This study highlights the influence of environment pressure (0.1 MPa to $3.5 \mathrm{MPa}$ ) in GTAW arc characters especially in arc morphology and electric characteristics. The arc shrinks and becomes brighter with the increasing pressure. Under elevated pressure, the electric characteristics are rising and the gradients are increasing slightly. The arc voltage is increased clearly like $37 \mathrm{~V}$ at $150 \mathrm{~A}$ which is almost 3 times higher than at $0.1 \mathrm{MPa}$. The analytic equation is also deduced based on the balance of heat-input and heat-output to verify the experimental results.

\section{Acknowledgement}

This research was financially supported by the National Natural Science Foundation of China (No. 51475102) and the
Fundamental Research Funds for the Central Universities (HIT.MKSTISP.201617).

\section{References}

[1] Majumdar J D 2006 Underwater Welding -Present Status and Future Scope Journal of Naval Architecture and Marine Engineering 3(1): 38-47

[2] Braestrup M, Andersen J B, Andersen L W, Bryndum M B and Nielsen N R 2005 Design and installation of marine pipelines. British Dental Journal 171(6):174-177

[3] Shukla A and Karki H 2016 Application of robotics in onshore oil and gas industry-A review Part I, Robotics and Autonomous Systems 75: 490-507

[4] Shukla A and Karki H 2016 Application of robotics in offshore oil and gas industry-A review Part II. Robotics and Autonomous Systems 75: 508-524

[5] Richardson I M, Woodward N J and Billingham J 2002 Deepwater Welding for Installation and Repair-A Viable Technology In: The Twelfth International Offshore and Polar Engineering Conference. International Society of Offshore and Polar Engineers

[6] Hutt G and PACHNIUK I 1993 Trends in diverless/remotely controlled hyperbaric pipeline tie-ins In: Proceedings of the... International Offshore and Polar Engineering Conference. International Society of Offshore and Polar Engineers, 2: 229-234

[7] Nixondg J and Billingham J 1987 A survey of underwater welding techniques. Endeavour 11(3): 143-148

[8] Dos Santos J F, Szelagowski P, Schafstall H G and Dobernowsky A 1990 Preliminary Investigations on the Effect of Short Circuit Variables on Metal Transfer Above 60 bar abs In: Offshore Technology Conference, Houston Texas, USA

[9] Dos Santos J F, Szelagowski P, Schafstall H G 1989 Properties of hyperbaric flux cored arc welds: weld metal chemistry In: OTC'89', 21st Annual Offshore Technology Conference, Houston Texas, USA

[10] Allum C J et al, 1982 Characteristics and Structure of High Pressure (1-42 bars) Gas Tungsten Arcs. Cranfield Institute of Technology

[11] Suga Y and Hasui A, 1990 Effects of Helium Pressure on Characteristics of TIG Arcs and Mechanical Properties of Welds. Transactions of the Japan Welding Society 21(1): 24-30

[12] Suga Y, 1989 On the arc welding under high pressure argon and helium atmosphere. Welding Under Extreme Conditions conference, Helsinki, pp 124-132

[13] Nixon J H 2000 In: Underwater repair technology Woodhead Publishing, Cambridge

[14] Jiang L, Wang Z H, Jiao X D, Zhou C F, Fang X M and Ma H X 2007 Characteristics of GTAW arc in underwater welding under high-pressure air condition. TransactionsChina Welding Institution 28(6): 1

[15] Chunjian Wang 2011 Research on The Arc Shape Under High Air Ambient Pressure. Beijing Institute of PetrolChemical Technology, Beijing, Master Dissertation

[16] Bauder U H 1976 Properties of high pressure arc plasma. Applied Physics 9(2): 105-115 